\title{
HUBUNGAN KETEPATAN TRIASE DENGAN RESPONSE TIME PERAWAT DI INSTALASI GAWAT DARURAT RUMAH SAKIT TIPE C
}

\author{
Jimmy F. Rumampuk \\ Mario E. Katuuk \\ Program Studi Ilmu Keperawatan Fakultas Kedokteran \\ Universitas Sam Ratulangi Manado \\ Email : jimmyfrumampuk@yahoo.com
}

\begin{abstract}
The most important thing when the nurse does triage is to do response time. A decrease in the triage scale assessment will extend the handling time that the patients should receive according to their clinical conditions so that it will risk reducing the patient safety rate and the quality of health services. The purpose of this study was to identify the relationship of the accuracy of triage with the response time of nurses in hospital type C Emergency Unit. Samples totaling 36 respondents were taken using total sampling technique. Method used observational analytic research design with a cross sectional approach. The result of study using fisher's exact test at a significance level of 95\%, obtained a significant value $p=0.003$ or smaller than $0.05(0.003<0.05)$. The conclusion of the results of this study indicate that there is a relationship between the accuracy of triage with the response time of nurses in the emergency room type $C$ hospital.
\end{abstract}

Keywords: Triage, Accuracy, Response Time, IGD

Abstrak : Hal terpenting ketika perawat melakukan triase adalah melakukan response time. Penurunan penilaian skala triase akan memperpanjang waktu penanganan yang seharusnya di terima oleh pasien sesuai dengan kondisi klinisnya sehingga akan beresiko menurunkan angka keselamatan pasien dan kualitas dari layanan kesehatan. Tujuan penelitian ini adalah untuk mengidentifikasi hubungan ketepatan triase dengan response time perawat di IGD rumah sakit tipe C. Sampel berjumlah 36 responden yang diambil menggunakan teknik total sampling. Desain Penelitian yang di gunakan adalah observasional yang bersifat analitik dengan pendekatan Cross Sectional. Hasil Penelitian uji fisher's exact test pada tingkat kemaknaan $95 \%$, diperoleh nilai signifikan $\mathrm{p}=0,003$ atau lebih kecil dari $0,05(0,003<0,05)$. Kesimpulan hasil penelitian ini menunjukan bahwa terdapat hubungan antara ketepatan triase dengan response time perawat di IGD rumah sakit tipe $\mathrm{C}$.

Kata Kunci : Triase, Ketepatan, Response Time, IGD 


\section{PENDAHULUAN}

Instalasi Gawat Darurat (IGD) merupakan titik masuk yang sangat penting untuk pelayanan kesehatan bagi pasien yang membutuhkan penanganan dan perawatan mendesak (Sunyoto dkk, 2014). Berdasarkan Keputusan Menteri Kesehatan Tahun 2009, Jumlah kunjungan ke RSU di Indonesia pada tahun 2007 sebanyak 33.094.000 dengan pasien yang melakukan kunjungan ke IGD sebanyak 4.402.205 atau $13,3 \%$ dari total seluruh kunjungan di RSU (Keputusan Menteri Kesehatan, 2009).

Triase merupakan hal penting dalam merawat dan melakukan penilaian awal pasien di IGD (Khairina, dkk. 2018). Tujuan utama dari triase adalah untuk menurunkan angka morbiditas dan mortalitas semua pasien gawat darurat (Garbez, et all. 2011). Penelitian Evie, dkk. (2016) didapatkan IGD rumah sakit tipe C Malang ada 27 orang $(77,1 \%)$ dari 35 responden yang tidak tepat melakukan pelaksanaan triase. Penelitian oleh Gustia dan Manurung (2018) tentang hubungan ketepatan penilaian triase dengan tingkat keberhasilan penanganan pasien cedera kepala di IGD RSU HKBP Balige Kabupaten Toba Samosir yang merupakan rumah sakit tipe $\mathrm{C}$ di Sumatra Utara didapatkan hasil keberhasilan penilaian triase sebesar 14 orang $(82.36 \%)$ dan di dapatkan adanya hubungan antara ketepatan penilaian triase dengan tingkat keberhasilan penanganan pasien cedera kepala.

Penurunan penilaian skala triase atau ketidaktepatan triase akan memperpanjang waktu penanganan yang seharusnya di terima oleh pasien sesuai dengan kondisi klinisnya dan kemudian akan beresiko menurunkan angka keselamatan pasien dan kualitas dari layanan kesehatan (Khairina, Marini \& Huriani, 2018). Pasien gawat darurat harus ditangani dengan waktu $<5$ menit (Keputusan Menteri Kesehatan, 2009). Response time yang memanjang dalam penanganan pasien gawat darurat dapat menurunkan usaha penyelamatan pasien (Maatilu, 2014). Penelitian yang dilakukan oleh Asmara dan Handayani (2017) tentang gambaran penyebab kematian di IGD terdapat 51 pasien $(44,3 \%)$ pasien meninggal di IGD dalam waktu $<24$ jam dari total 115 pasien.

Penelitian oleh Putri dan Fitria (2018) mengenai hubungan kecepatan dan ketepatan terhadap life saving pasien trauma kepala menunjukan adanya hubungan yang signifikan antara response time dengan life saving pasien trauma kepala dimana semakin cepat response time maka semakin naik life saving pasien cedera kepala. Penelitian yang dilakukan oleh Tumbuan (2015) hasil response time perawat dalam menangani kasus gawat darurat di IGD RSU GMIM Kolooran Amurang yang adalah rumah sakit tipe $\mathrm{C}$ kebanyakan $(57,1 \%)$ lambat.

Hasil penelitian dari Apriani dan Febriani (2017) di IGD RSI Siti Khadijah Palembang yang merupakan rumah sakit tipe $\mathrm{C}$ di dapatkan hasil ada hubungan yang signifikan antara kegawatdaruratan dengan waktu tanggap (response time). Fenomena yang terjadi di Instalasi Gawat Darurat (IGD) yakni penerapan triase belum dilakukan dengan maksimal sehingga masih banyak pasien yang tidak memperoleh penanganan yang cepat dan tepat sesuai dengan kondisinya. Ketidaktepatan triase tersebut akhirnya menyebabkan memanjangnya response time dalam melaksanakan tindakan pelayanan awal di IGD.

Data awal yang diperoleh peneliti pada bulan Oktober 2018 di instalasi gawat darurat RSU GMIM Pancaran Kasih Manado, rumah sakit tipe $\mathrm{C}$ dengan jumlah perawat di IGD berjumlah 24 orang yang semuanya telah mengikuti pelatihan dasar kegawatdaruratan, total jumlah kunjungan pasien harian berkisar 50-60 orang dalam 3 bulan yakni bulan Mei 1.501 pasien, Juni 1.641 pasien, Juli 1547 jadi rata-rata pasien yang berkunjung ke IGD mencapai> 1.500 orang pasien, kemudian pada bulan Desember 2018 data awal yang di peroleh peneliti di RSU GMIM Bethesda Tomohon, rumah sakit tipe $\mathrm{C}$ dengan jumlah 
kunjungan pasien rata-rata per bulan sekitar 1500 pasien dan jumlah perawat IGD 16 orang perawat yang semuanya juga telah mengikuti pelatihan dasar kegawatdaruratan.

Hasil observasi di IGD kedua rumah sakit tersebut terdapat ruang triase, ruang resusitasi dan ruang tindakan dan ruang ponek dengan lajur warna triase pada lantai. Peneliti telelakukan wawancara dengan kepala ruangan di tempat mengenai penerapan triase di IGD kedua rumah sakit tersebut belum sepenuhnya melakukan triase dengan baik, sehingga terjadi perpanjangan response time dalam penanganan awal pasien. Kedua rumah sakit ini memiliki standar yang sama yakni $<5$ menit. Berdasarkan fenomena di atas maka peneliti tertarik untuk melakukan penelitian mengenai "Hubungan Ketepatan Triase dengan Response Time Perawat di Instalasi Gawat Darurat (IGD) Rumah Sakit Tipe C."

\section{METODE PENELITIAN}

Jenis penelitian ini adalah penelitian observasional yang bersifat analitik dengan menggunakan desain Cross Sectional yaitu data penelitian dikumpulkan sesuai kondisi pada saat suatu penelitian berlangsung, sehingga pengumpulan data hanya di lakukan sekali dengan tidak melihat kejadian masa lalu atau kejadian yang akan datang (Siswanto dkk, 2016). Penelitian ini telah dilakukan di IGD RSU GMIM Pancaran Kasih Manado dan IGD RSU GMIM Bethesda Tomohon pada bulan Oktober - Desember 2018. Populasi dalam penelitian ini adalah perawat yang bekerja di IGD RSU GMIM Pancaran Kasih Manado berjumlah 24 orang dan RSU GMIM Bethesda Tomohon berjumlah 16 orang dengan total 40 orang. Pengambilan sampel pada penelitian ini menggunakan teknik total sampling. Sampel pada penelitian ini berjumlah 36 orang yang memenuhi kriteria inklusi : perawat yang bekerja di IGD, perawat yang bersedia menjadi responden dan menandatangani surat persetujuan. Kriteria Ekslusi : Perawat yang sedang cuti, perawat yang memegang jabatan organisasi (kepala ruangan).

Instrumen dalam penelitian ini menggunakan check list lembar observasi dengan pengukuran data yang digunakan yaitu skala Guttman. Lembar observasi ketepatan triase berisi tentang standar operasional trise yang di gunakan di instalasi gawat darurat (IGD) RSU GMIM Pancaran Kasih Manado dan RSU GMIM Bethesda Tomohon. Penilaian dalam lembar observasi ini yaitu "Sesuai" dan tidak sesuai". Selanjutnya ketepatan triase dikatakan tepat jika pada akhir observasi semua prosedur dilakukan sesuai kategori triase dan tidak tepat jika satu atau lebih perosedur tidak dilakukan. Kemudian menggunakan lembar observasi dan stopwatch. Lembar observasi response time berisi tentang waktu tanggap (response time) yang di terima setiap pasien yang diukur dengan menggunakan stopwatch.Standar waktu yang digunakan yakni $\leq 5$ menit sesuai dengan Keputusan Kementerian Kesehatan Republik Indonesia tahun 2009. Penilaian dalam lembar observasi ini yaitu "cepat $(\leq 5$ menit)" dan "lambat (> 5 menit)".

Pengolahan data yang diperoleh dari hasil penelitian ini diolah secara manual dengan mengelompokan hasil dari lembar obsevasi kemudian dilakukan analisis menggunakan uji statistik setelah itu diolah menggunakan sistem komputerisasi, tahaptahap tersebut yaitu editing, coding, processing, dan cleaning. (Setiadi, 2013) Data dianalisis melalui analisis univariat dan bivariat dengan menggunakan uji Fisher's Exact Test dengan tingkat kepercayaan $95 \%$ derajat kemaknaan $\alpha=$ 0,05. untuk melihat hubungan antara masing-masing variabel independen dengan variabel dependen. 
HASIL dan PEMBAHASAN

Karakteristik Responden

Tabel 1. Distribusi Frekuensi Responden Menurut Jenis Kelamin

\begin{tabular}{ccc}
\hline Jenis Kelamin & n & \% \\
\hline Laki-laki & 9 & 25 \\
Perempuan & 27 & 75 \\
\hline Total & $\mathbf{3 6}$ & $\mathbf{1 0 0}$ \\
\hline
\end{tabular}

Sumber : Data Primer, 2018

Berdasarkan jenis kelamin menunujukan bahwa dari total 36 responden $(100 \%)$ jenis kelamin perempuan merupakan jenis kelamin yang terbanyak dengan jumlah 27 orang (75\%) sementara untuk responden yang berjenis kelamin laki-laki berjumlah 9 orang $(25 \%)$. Pekerjaan perawat masih banyak diminati oleh perempuan dibandingkan laki-laki karena keperawatan masih diidentikkan dengan pekerjaan yang cocok dan sesuai dengan sifat perempuan yang lebih sabar, lemah lembut, dan peduli (Yanti \& Warsito, 2013).

Tabel 2. Distribusi Frekuensi Responden Menurut Usia

\begin{tabular}{ccc}
\hline Umur & n & \% \\
\hline $21-31$ tahun & 31 & 86,1 \\
$32-42$ tahun & 5 & 13,9 \\
\hline Total & $\mathbf{3 6}$ & $\mathbf{1 0 0 , 0}$ \\
\hline
\end{tabular}

Sumber : Data Primer, 2018

Distribusi frekuensi responden dilihat dari karakteristik usia, hasil menunjukan bahwa dari total 36 responden $(100 \%)$ yang memiliki usia 21-31 tahun sebanyak 31 orang $(86,1 \%)$ dan yang memiliki usia $32-$ 42 tahun sebanyak 5 orang (13,9\%). penelitian yang dilakukan oleh Fitriyanti dan Suryati (2016) menenai hubungan karakteristik perawat dengan kinerja perawat di RSKD Duren Sawit Jakarta Timur didapatkan sebanyak 24 perawat (52,2\%) ada pada usia 20-33 tahun dan 22 perawat $(47,8 \%)$ ada pada usia 34-44 tahun dengan hasil ada hubungan usia dengan kinerja perawat.
Tabel 3. Distribusi Frekuensi Responden Menurut Tingkat Pendidikan

\begin{tabular}{ccc}
\hline $\begin{array}{c}\text { Tingkat } \\
\text { Pendidikan }\end{array}$ & n & \% \\
\hline S1 Ners & 9 & 25,0 \\
D4 Keperawatan & 1 & 2,8 \\
D3 Keperawatan & 26 & 72,2 \\
\hline Total & $\mathbf{3 6}$ & $\mathbf{1 0 0}$ \\
\hline
\end{tabular}

Sumber : Data Primer, 2018

Hasil penelitian pada tabel 3 karakteristik tingkat pendidikan, hasil penelitian menunjukan bahwa dari total 36 responden (100\%) dengan tingkat pendidikan D3 Keperawatan merupakan yang terbanyak yakni 26 orang $(72,2 \%)$ kemudian dengan tingkat pendidikan S1 Ners sebanyak 9 orang (25\%) dan 1 orang dengan tingkat pendidikan D4 Keperawatan. pendidikan yang tinggi dapat meningkatkan keterampilan perawat, juga semakin tinggi pendidikan seseorang maka semakin kritis, logis dan sistematis cara berpikirnya, serta semakin tinggi kualitas kerjanya (Fitrianty \& Suryati 2016).

\section{Analisis Univariat}

Tabel 4. Distribusi Frekuensi Responden Menurut Ketepatan Pelaksanaan Triase

\begin{tabular}{ccc}
\hline $\begin{array}{c}\text { Ketepatan } \\
\text { Triase }\end{array}$ & $\mathbf{n}$ & $\mathbf{\%}$ \\
\hline Tepat & 22 & 61,1 \\
Tidak Tepat & 14 & 38,9 \\
\hline Total & $\mathbf{3 6}$ & $\mathbf{1 0 0 , 0}$ \\
\hline
\end{tabular}

Sumber : Data Primer, 2018

Tabel 4 menunjukan bahwa dari total 36 responden (100\%) terdapat sebanyak 22 orang $(61,1 \%)$ yang melakukan triase dengan tepat dan sebanyak 14 orang $(38,9 \%)$ yang tidak tepat melakukan triase. Tujuan utama triase adalah untuk meminimalisasi terjadinya cedera dan kegagalan selama proses penyelamatan pasien. Hasil penelitian oleh Gustia dan Manurung (2018) tentang hubungan ketepatan penilaian triase dengan tingkat keberhasilan penanganan pasien cedera kepala di IGD RSU HKBP Balige Kabupaten Toba Samosir yang merupakan 
rumah sakit tipe $\mathrm{C}$ di Sumatra didapatkan hasil keberhasilan penilaian triase sebesar 14 orang $(82.36 \%)$ dan di dapatkan adanya hubungan antara ketepatan penilaian triase dengan tingkat keberhasilan penanganan pasien cedera kepala. Namun berbeda dengan hasil penelitian Evie, dkk. (2016) didapatkan IGD rumah sakit tipe $\mathrm{C}$ malang ada 27 orang $(77,1 \%)$ dari 35 responden yang tidak tepat pelaksanaan triase dikarenakan faktor yang berhubungan dengan penelitian ini yakni pelatihan kegawatdaruratan oleh perawat.

Ketepatan pelaksanaan triase perawat baik di dukung oleh hasil observasi peneliti di rumah sakit dimana pelaksanaan triase di kedua rumah sakit tersebut berjalan baik karena perawat memiliki pengetahuan yang luas dilihat dari tingkat pendidikan perawat pada kedua rumah sakit tersebut sebagian besar D3 Keperawatan 26 orang (72,2\%) kemudian dengan tingkat pendidikan S1 Ners sebanyak 9 orang (25\%) dan 1 orang dengan tingkat pendidikan D4 Keperawatan juga semua responden telah mengikuti pelatihan dasar kegawatdaruratan serta adanya penilaian akreditasi rumah sakit yang membuat seluruh pelayanan rumah sakit harus sesuai dengan standar oprasional. Sumarno (2017) menyatakan bahwa pelayanan kesehatan sesuai prosedur merupakan salah satu indikator menilai tepatnya pelaksanaan pelayanan dari suatu rumah sakit, yang dapat memberikan dampak yang baik bagi pasien maupun bagi petugas dan rumah sakit jika dilaksanakan sebagaimana mestinya tapi jika tidak dilakukan sesuai dengan standart prosedur dari rumah sakit tersebut maka akan berdampak tidak baik bagi pasien, petugas maupun rumah sakit itu sendiri.
Tabel 5. Distribusi Frekuensi Responden Menurut Response Time perawat

\begin{tabular}{ccc}
\hline $\begin{array}{c}\text { Response } \\
\text { Time }\end{array}$ & n & $\%$ \\
\hline Cepat & 10 & 27,8 \\
Lambat & 26 & 72,2 \\
\hline Total & $\mathbf{3 6}$ & $\mathbf{1 0 0 , 0}$ \\
\hline
\end{tabular}

Sumber : Data Primer, 2018

Disitribusi responden pada tabel 5 menunjukan bahwa dari total 36 responden (100\%) paling banyak memiliki response time yang lambat yakni sebanyak 26 orang $(72,2 \%)$ dan yang memiliki response time cepat hanya ada sebanyak 10 orang (27,8\%). Waktu tanggap (response time) pelayanan merupakan gabungan antara waktu tanggap saat pasien tiba di depan pintu rumah sakit sampai pasien mendapatkan penanganan awal atau respon dari petugas instalasi gawat darurat dengan waktu yang digunakan sampai selesai pasien diberi pertolongan (Sutriningsih, 2016). Penelitian yang dilakukan oleh Tumbuan (2015) hasil response time perawat dalam menangani kasus gawat darurat di IGD RSU GMIM Kolooran Amurang yang juga rumah sakit tipe $\mathrm{C}$ kebanyakan $(57,1 \%)$ lambat. Hal ini tidak sesuai dengan Keputusan Menteri Kesehatan (2009) yang menyatakan bahwa pasien gawat darurat harus ditangani dalam waktu $<5$ menit.

Hasil observasi peneliti di kedua rumah sakit, didapatkan banyak pasien yang datang namun kurangnya petugas kesehatan khususnya perawat di IGD lebih khusus di ruang triase sehingga menyebabkan proses dari awal triase sampai pasien mendapatkan penanganan awal mengalami keterlambatan waktu. Selanjutnya tidak meratanya tingkat kegawatan yang datang kebanyakan adalah kategori triase kuning dan hijau sesuai dengan Fadhilah, dkk. (2013) menyatakan bahwa tidak meratanya penyebaran tingkat kegawatan, keberadaan petugas yang ada di triase, ketersediaan sarana dan cara bayar pasien merupakan beberapa faktor yang menyebabkan waktu tanggap (Response time) melebihi dari standar yang telah di 
tetapkan. Selanjutnya penelitian yang dilakukan oleh Mahyawati (2015) tentang hubungan kegawatdaruratan pasien dengan waktu tanggap perawat di IGD RS PKU Muhammadyah Yogyakarta di simpulkan bahwa terdapat hubungan antara kegawat daruratan dengan waktu tanggap dimana semakin tinggi tingkat kegawatan pasien maka waktu tanggap akan semakin cepat.

Minimnya tempat tidur dan kursi roda di ruang triase serta persediaan obat-obatan dan stratcher di IGD. Keterlambatan response time perawat akan berdampak buruk bagi pasien serta pelayanan rumah sakit banyak faktor namun yang paling penting diantaranya ialah pelaksanaan triase, kesediaan sarana prasarana rumah sakit dan layanan kesehatan penunjang lainnya.

\section{Analisis Bivariat}

Tabel 6. Analisis Hubungan Ketepatan Triase dengan Response Time

\begin{tabular}{cccccccc}
\hline \multirow{2}{*}{$\begin{array}{c}\text { Ketepatan } \\
\text { Triase }\end{array}$} & \multicolumn{3}{c}{ Response Time } & \multicolumn{2}{c}{ Total } & \multirow{2}{*}{ Pv } \\
\cline { 2 - 6 } & $\mathbf{2}$ & $\mathbf{\%}$ & $\mathbf{n}$ & $\mathbf{\%}$ & $\mathbf{n}$ & $\mathbf{\%}$ & \\
\hline \multirow{2}{*}{ Tepat } & 1 & 27, & 1 & 33, & 2 & 61, & \\
Tidak & 0 & 8 & 2 & 3 & 2 & 1 \\
Tepat & 0 & 0 & 1 & 38, & 1 & 38, & \\
& & 4 & 9 & 4 & 9 & \multirow{2}{*}{$\mathbf{0 , 0 0 3}$} \\
Total & $\mathbf{1}$ & $\mathbf{2 7}$, & $\mathbf{2}$ & $\mathbf{7 2 ,}$ & $\mathbf{3}$ & \multirow{2}{*}{$\mathbf{1 0 0}$} & \\
& $\mathbf{0}$ & $\mathbf{8}$ & $\mathbf{6}$ & $\mathbf{2}$ & $\mathbf{6}$ & & \\
\hline
\end{tabular}

Sumber : Data Primer, 2018

Analisis hubungan antara ketepatan triase dan response time pada tabel 6 menunjukan bahwa dari total responden 36 orang $(100 \%)$ terdapat 22 orang $(61 \%)$ yang melakukan triase dengan tepat memiliki response time yang cepat sebanyak 10 orang $(27,8 \%)$ sementara dengan response time lambat sebanyak 12 orang $(33,3 \%)$ sementara untuk responden yang melakukan triase dengan tidak tepat memiliki response time yang lambat sebanyak 14 orang $(38,9 \%)$ dan dengan tidak ada yang memiliki response time yang cepat $(0 \%)$. Hasil uji hipotesis yang dilakukan menggunakan uji fisher's exact test menunjukan nilai $\mathrm{p}=0,003<\alpha=0,05$. Dengan demikian dapat disimpulkan bahwa terdapat hubungan yang signifikan antara ketepatan triase dengan response time perawat di IGD Rumah Sakit tipe C.

Hasil penelitian ini didukung oleh Mardalena (2017) yang menyatakan bahwa Response Time sangat berhubungan dengan triase di mana hal terpenting ketika perawat melakukan triase adalah melakukan response time. Mahyawati (2015) tentang hubungan kegawatdaruratan pasien dengan waktu tanggap perawat di IGD RS PKU Muhammadyah Yogyakarta di simpulkan bahwa terdapat hubungan antara kegawat daruratan dengan waktu tanggap dimana semakin tinggi tingkat kegawatan pasien maka waktu tanggap akan semakin cepat. Penelitian ini menunjukan bahwa dari total responden 36 orang $(100 \%)$ terdapat 22 orang $(61 \%)$ yang melakukan triase dengan tepat memiliki response time yang cepat sebanyak 10 orang $(27,8 \%)$ sementara dengan response time lambat sebanyak 12 orang $(33,3 \%)$. Hal ini terjadi karena adanya faktor lain yang menyebabkan response time lambat seperti karakteristik jenis kelamin dan umur.

Berdasarkan hasil penelitian responden yang berjenis kelamin perempuan lebih banyak yakni 27 orang (75\%) dibanding laki-laki yang hanya berjumlah 9 orang (25\%) dengan usia terbanyak ada pada rentang dewasa muda yakni 21-31 tahun $(86,1 \%)$. Menurut penelitian Rahil (2012) jenis kelamin laki-laki memiliki response time yang cepat dibanding perempuan dikarenakan laki-laki memiliki keunggulan fisik dan faktor usia berhubungan dengan response time perawat dimana perawat usia 40-60 tahun memiliki response time yang lebih cepat dari perawat 20-40 tahun dikarenakan semakin bertambah usia maka semakin bertambah kedewasaannya.

Hasil observasi peneliti di kedua rumah sakit faktor yang lain di dapatkan kurangnya tenaga kesehatan khususnya perawat di ruangan IGD dimana hanya ada 21 orang perawat diluar kepala ruangan di IGD RSU GMIM Pancaran Kasih Manado dan 15 orang perawat diluar kepala ruangan di IGD RSU GMIM Bethesda Tomohon sementara kunjungan pasien di setiap bulan 
mencapai 1500 orang dan kunjungan harian sebanyak 50-60 orang dan tidak merata pada setiap shiftnya sehingga perawat terlihat kewalahan dalam menangani pasien. Sesuai dengan Dadashzadeh, et all. (2013) menjelaskan bahwa salah satu faktor yang berhubungan dengan pelaksanaan triase adalah rasio jumlah perawat dan pasien. Tidak berimbangnya antara ketersediaan sumber daya manusia dengan jumlah kunjungan pasien yang banyak akan berpotensi pada penundaan penanganan pasien sehingga akan berdampak fatal bahkan mematikan bagi pasien dengan kondisi emergency ( Evie, dkk. 2016). Faktor lainnya adalah lamanya waktu yang di butuhkan saat mekukan pengkajian awal di ruang triase kebanyakan responden tidak memperhatikan waktu pengkajian, kemudian kurangnya sarana prasarana seperti tempat tidur dan kursi roda sehingga tertunda di beri tindakan maka dari itu terjadi perpanjangan waktu response time.

Hasil crosstab penelitian untuk responden yang melakukan triase dengan tidak tepat memiliki response time yang lambat sebanyak 14 orang $(38,9 \%)$ dan dengan tidak ada yang memiliki response time yang cepat $(0 \%)$. Hal ini terjadi karena menurunnya penilaian skala triase dapat memperpanjang waktu penanganan yang seharusnya di terima oleh pasien sesuai dengan kondisi klinisnya dan kemudian akan beresiko menurunkan angka keselamatan pasien dan kualitas dari layanan kesehatan (Khairina, Marini \& Huriani, 2018).

Berdasarkan hasil observasi peneliti di kedua rumah sakit ruang IGD telah memiliki alur triase dan ruangan-ruang seperti ruang triase, resusitasi, observasi, ponek, tindakan bedah serta lajur warna triase di lantai IGD nya. Sebagian besar responden telah melakukan triase dengan baik sesuai dengan 5 poin yang dilihat pada lembar observasi ketepatan triase yakni 1 . Pasien datang diterima petugas/paramedis, 2. Di ruang triase dilakukan anamnesis, 3 . Penetuan derajat kegawatan, 4. Pembagian pelayanan prioritas , 5. Penaganan pasien sesuai prioritas. Paling banyak responden baik dalam pelaksanaan triase yaitu pada poin 1 dan 5 yaitu pasien datang diterima petugas/paramedis dan pasien diberikan penanganan sesuai dengan prioritasnya kemudian diikuti poin 3 penentuan derajat kegawatan pasien dimana setiap pasien yang datang langsung di berikan penilaian / kode warna sesuai dengan tingkat kegawatan kemudian.

Responden yang tidak tepat pada pelaksanaan triase ada pada poin 2 dan poin 4 yaitu pemeriksaan / anamnesa seringkali tidak dilakukan di ruangan triase tetapi di ruang lainnya seperti ruang observasi dan resusitasi. Kemudian pembagian pelayanan prioritas dimana untuk pelayanan pada prioritas hijau dan kuning sering kali tidak sesuai. Penelitian Sulistyawati dan Handayani (2017) di dapatkan hasil kesimpulan ada hubungan antara tingkat kegawatan pasien dengan waktu tanggap perawat di Instalasi Gawat Darurat RS X kediri di mana pasien dengan tingkat kegawatan gawat darurat (triase merah) sebanyak 9 orang $(39,1 \%)$ dengan waktu tanggap cepat dan $0 \%$ untuk waktu tanggap lambat, kemudian dengan tingkat darurat tidak gawat (triase kuning) sebanyak 6 orang $(26,1 \%)$ dengan waktu tanggap cepat dan 4 orang $(17,4 \%)$ lambat, serta tingkat tidak gawat tidak darurat sebanyak 1 orang $(4,3 \%)$ dengan waktu tanggap cepat dan 3 orang $(13 \%)$ lambat.

Pelaksanaan triase sangat mempengaruhi response time, jika triase tidak dilakukan dengan tepat maka akan memperlambat waktu tanggap (response time) yang akan diterima pasien sehingga akan meningkatkan resiko kerusakan organ atau kecacatan, dan bahkan sampai pada kematian pasien. Selain itu juga akan berpengaruh pada kualitas pelayanan kesehatan rumah sakit dan akan menambah biaya perawatan pasien tersebut. 


\section{SIMPULAN}

1. Pelaksanaan triase di IGD rumah sakit Tipe $\mathrm{C}$ dilakukan dengan tepat.

2. Response Time di IGD rumah sakit Tipe $\mathrm{C}$ termasuk kategori lambat.

3. Terdapat hubungan yang signifikan antara ketepatan triase dengan response time di IGD rumah sakit tipe C.

\section{DAFTAR PUSTAKA}

Asmara, K., Handayani, T., N. (2017). Gambaran Kematian di Instalasi Gawat Darurat. Program Studi Ilmu Keperawatan Fakultas Keperawatan Universitas Syiyah Kuala Banda Aceh

Dadashzadeh, A., Abdolahzadeh, F., Rahmani, A., Gojazadeh, M. (2013) Factors Effecting triage decision making from the viewpoints of emergency department staff in Tabriz hospital. Iran Critical Care Nursing Journal, 6 (4) 269-276

Evie, S., Wihastuti, T, A., Suharsono, T. (2016) Analisis Faktor yang Berhubungan dengan Pelaksanaan Triase Perawat Pelaksana di Ruang IGD Rumah Sakit Tipe C Malang.Program Studi Magister Keperawatan Universitas Briwijaya. Jurnal Ilmiah Kesehatan Keperawatan, Volume 12, No.3

Fadhilah, N., Harahap, W. A., Lestari, Y. (2013). Faktor-Faktor yang Berhubungan dengan Waktu Tanggap pada Pelayanan Kasus Kecelakaan Lalu Lintas di Instalasi Gawat Darurat Rumah Sakit Umum Pusat Dr. M. Djamil Padang. Fakultas Kedokteran Universitas

Fitriyanti,L., Suryati, S. (2016) Hubungan Karakterisik Perawat dengan Motivasi Kerja dalam Pelaksanaan Terapi Aktifitas Kelompok di Rumah Sakit Khusus Daerah Duren Sawit Jakarta Timur. Jurnal Artikel Ilmu
Kesehatan Vol. 8 No.1 Fakultas Kesehatan MH Thamrin

Garbez, R., Carrieri-Kohlman, V., Stotts, N., Chan, G., \& Neighbor, M. (2011). Factors Influencing Patient Assignment to Level 2 and Level 3 Within the 5-Level ESI Triage System. Journal of Emergency Nursing, 37(6), 526-532.

Gustia, M., Manurung, M. (2018). Hubungan Ketepatan Penilaian Triase dengan Tingkat Keberhasilan Penanganan Pasien Cedera Kepala di RSU HKBP Balige Kabupaten Toba Simosir. Jurnal JUMANTIK Vol. 3 No. 2

Keputusan Menteri Kesehatan Republik Indonesia. (2009). Standar Instalasi Gawat Darurat (IGD) Rumah Sakit. Jakarta : Menteri Kesehatan Republik Indonesia

Khairina, I., Malini, H., Huriani, E. (2018). Faktor-Faktor Yang Berhubungan Dengan Pengambilan Keputusan Perawat Dalam Ketepatan Triase Di Kota Padang. Fakultas Keperawatan Universitas Andalas Indonesia. Indonesian Journal For Health Science Vol.02, No.01

Maatilu, V., Mulyadi., Malara, R. T. (2014). Faktor-Faktor Yang Berhubungan dengan respon time perawat pada penanganan pasien gawat darurat di IGD RSUP Prof Dr. R. D. Kandou Manado. Fakultas Kedokteran Program Studi Ilmu Keperawatan Universitas Sam Ratulangi Manado. E-jurnal Keperawatan (e-Kep)

Mahyawati, Widaryati. (2015). Hubungan kegawatdaruratan pasien dengan waktu tanggap perawat di IGD RS PKU Muhamadyah Yogyakarta. Naskah Publikasi. Program Studi Ilmu Keperawatan STIKES 'Aisyiyah Yogyakarta. 
Mardalena, Ida. (2017) Asuhan Keperawatan Gawat Darurat. Yogyakarta: Pustaka Baru Press.

Putri,D., Fitria, C., N. (2018). Ketepatan dan Kecepatan Terhadap Life Saving Pasien Trauma Kepala. Jurnal The $7^{\text {th }}$ University Research Colloqium 2018 STIKES PKU Muhammadiyah Surakarta

Rahil, N, H. (2012). Faktor-Faktor yang Berhubungan dengan Lama Waktu Tanggap Perawat pada Penanganan Asma di Instalasi GAwat Darurat RSUD Panembahan Senopati Bantul. Jurnal Respati Yogyakarta

Setiadi, I. (2013). Konsep dan Praktik Penulisan Riset Keperawatan. Yogyakarta : Graha Ilmu

Siswanto, Susila, Suyanto. (2016).Metodologi Penelitian Kesehatan dan Kedokteran. Yogyakarta: Bursa Ilmu

Sulistyawati, W., Handayani, O.V. (2017). Hubungan Tingkat KegawatanPasien Dan Beban Kerja Perawat Dengan Waktu Tanggap Perawat Di Instalasi Gawat Darurat. Jurnal Universitas Kediri Vol.01 No.1

Sumarno, M. S. S. (2017). Hubungan Ketepatan Pelaksanaan Triase dengan Tingkat Kepuasan Keluarga Pasien di Instalasi Gawat Darurat RSUP Praf. Dr. R. D. Kandou Manado. Fakultas Kedokteran Program Studi Ilmu Keperawatan Universitas Sam Ratulangi Manado. E-Journal Keperawatan (e-Kp) Volume 5 No.1

Sutriningsih D, S., Susilo, C., Hamid M, A. (2016). Penerapan Response Time Dalam Pelaksanaan Penentuan Prioritas Penanganan Kegawat daruratan Pada Pasien Kecelakaan Di IGD RSD Balung. Jurnal Fakultas
Ilmu Kesehatan Universitas Muhammadiyah Jember, Vol.6 No.2

Tumbuan, A. N. (2015). Hubungan Response Time Perawat dengan Tingkat Kecemasan Pasien Kategori Triase Kuning di IGD RSU GMIM Kalooran Amurang. Fakultas Kedokteran Program Studi Ilmu Keperawatan Universitas Sam Ratulangi Manado. E-Journal Keperawatan (e-Kp) Volume 3 No.2

Yanti, Warsito. (2013) . Hubungan Karakteristik Perawat, Motivasi Dengan Kualitas Dokumentasi Proses Asuhan Keperawatan. Jurnal Keperawatan 